Supplement of Nat. Hazards Earth Syst. Sci., 20, 877-888, 2020

https://doi.org/10.5194/nhess-20-877-2020-supplement

(C) Author(s) 2020. This work is distributed under

the Creative Commons Attribution 4.0 License.

(c) (1)

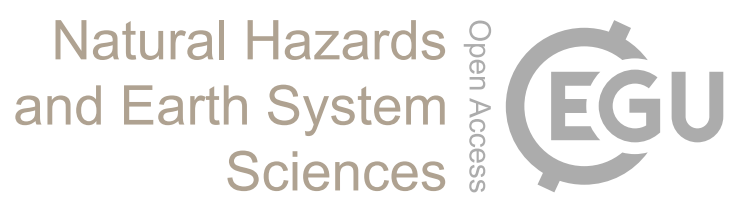

Supplement of

\title{
Predictive skill for atmospheric rivers in the western Iberian Peninsula
}

\author{
Alexandre M. Ramos et al. \\ Correspondence to: Alexandre M. Ramos (amramos@fc.ul.pt)
}

The copyright of individual parts of the supplement might differ from the CC BY 4.0 License. 
Supplementary Material
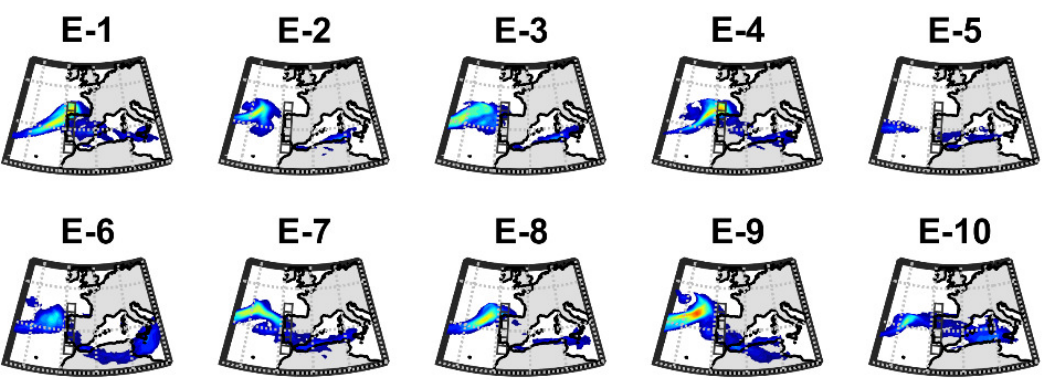

E-8

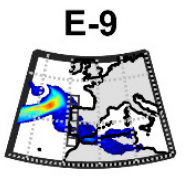

E-10

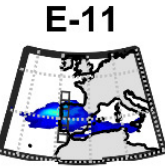

E-12
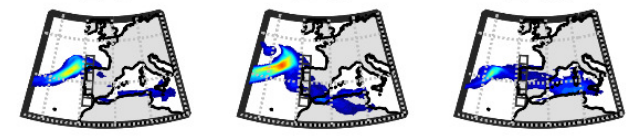

E-16

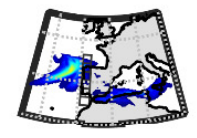

E-13

E-14

E-15
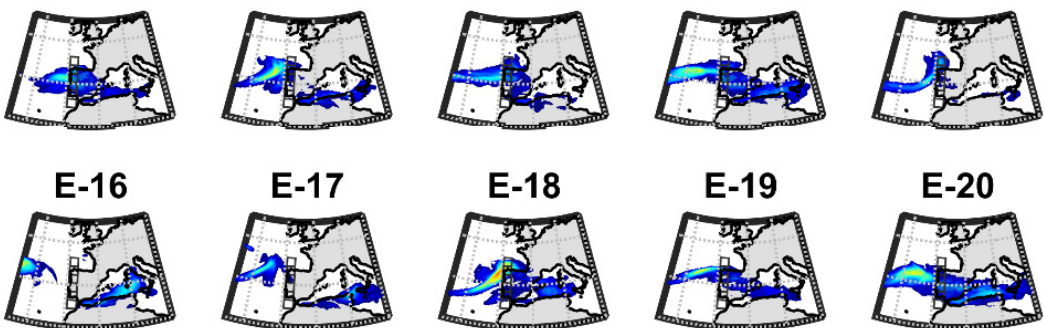

E-17

E-18

E-19

E-20
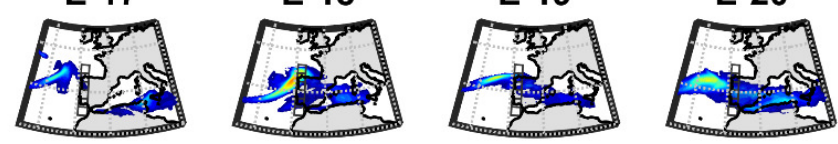

E-21

E-22

E-23

E-24

E-25
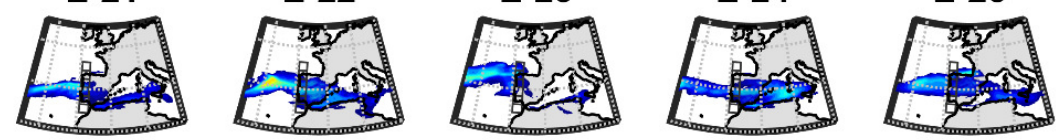

E-26

E-27

E-28

E-29

E-30
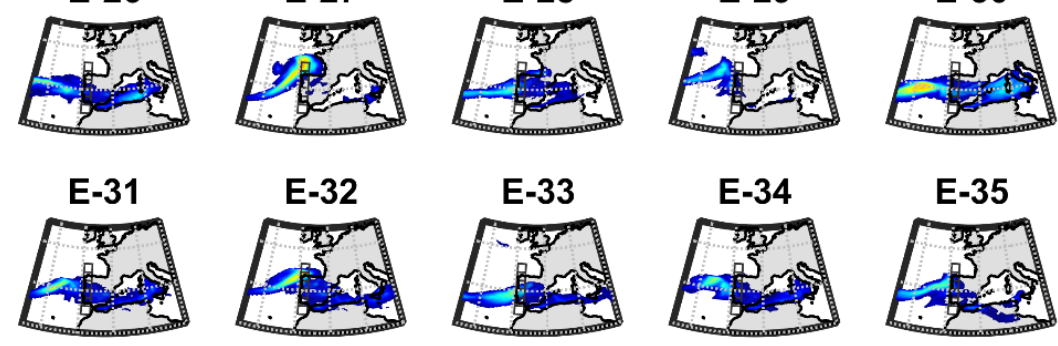

E-34

E-35
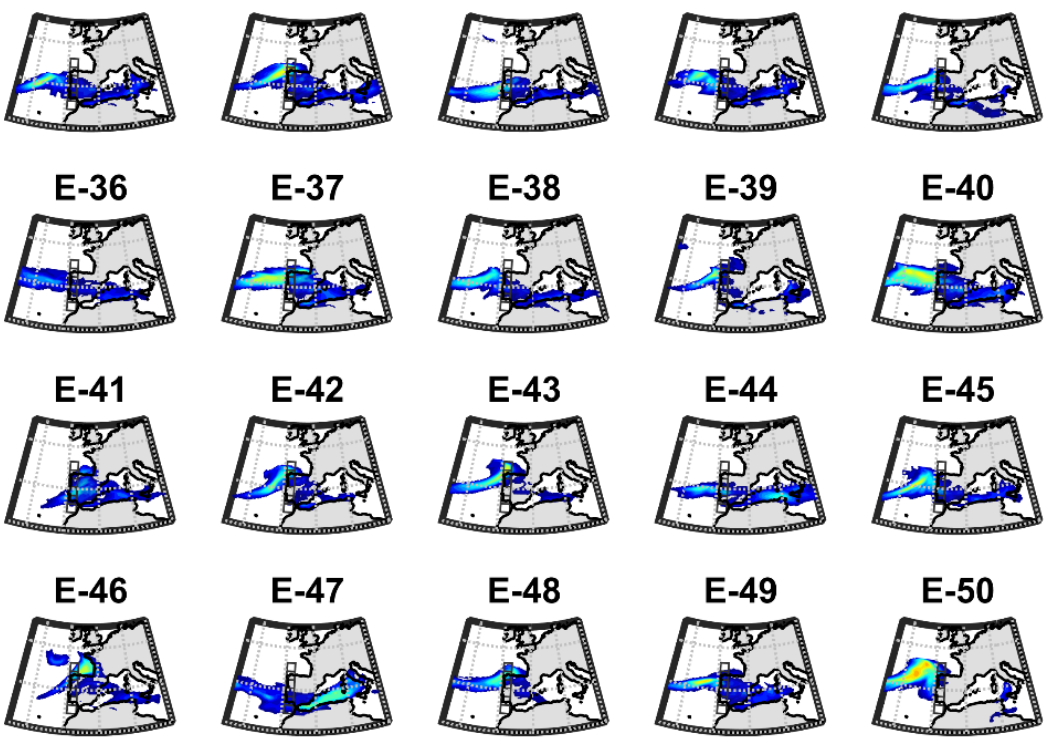

E-49

E-50
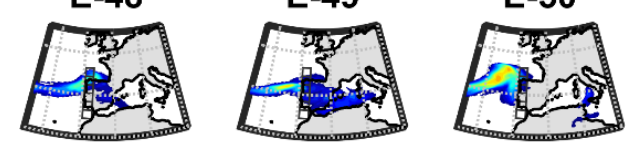

Figure S1. Ensemble forecast of the IVT in an event affecting Western Iberia on January 42016 for lead time -5 days. 


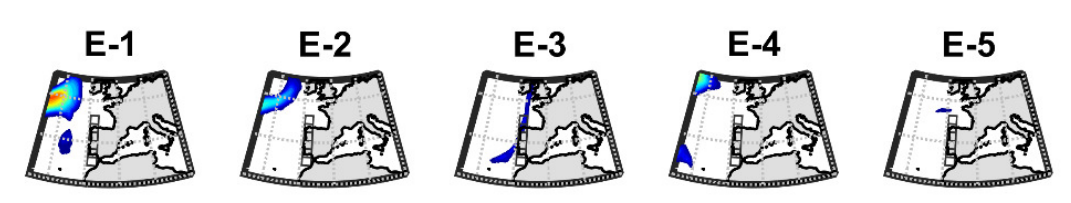

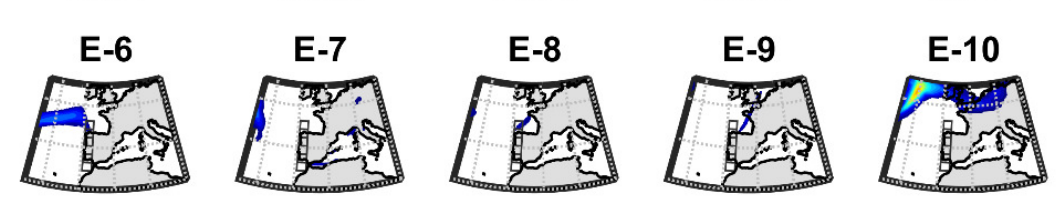

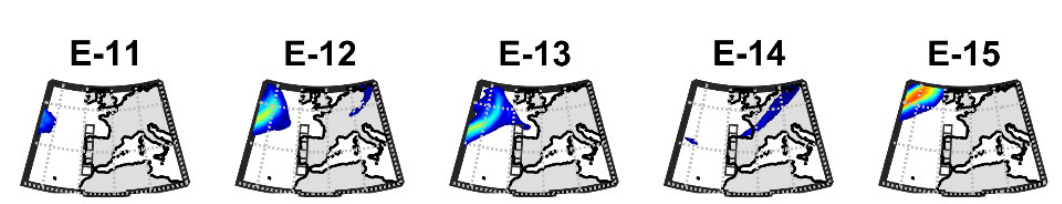

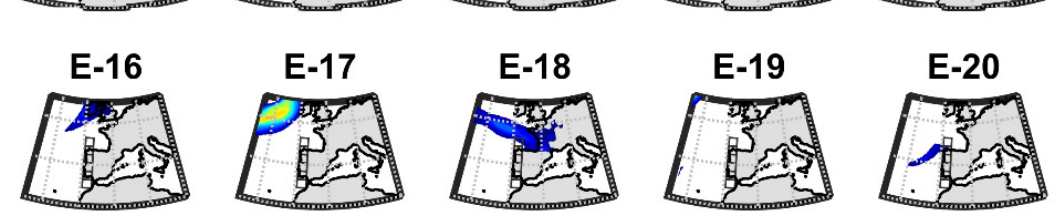

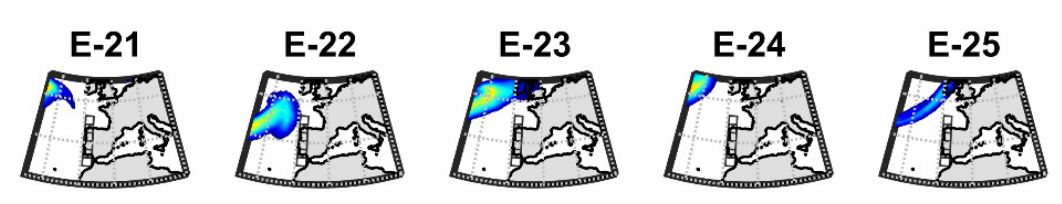

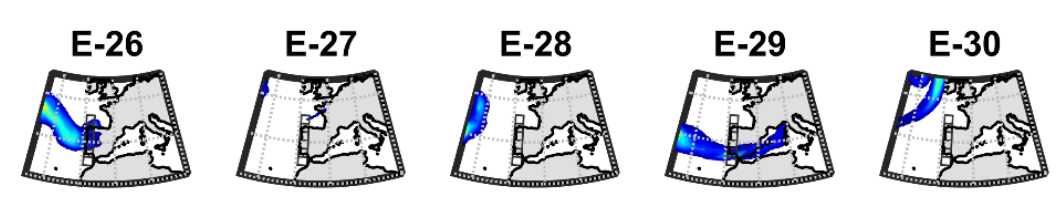

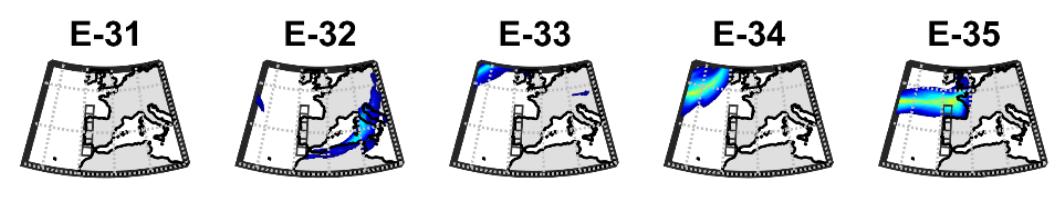

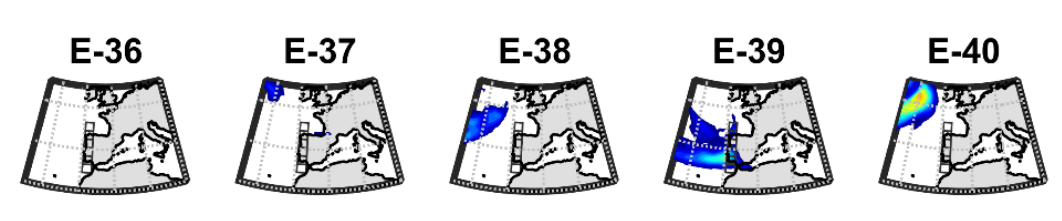

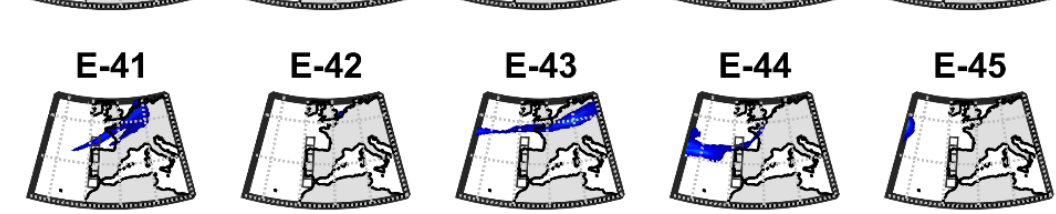

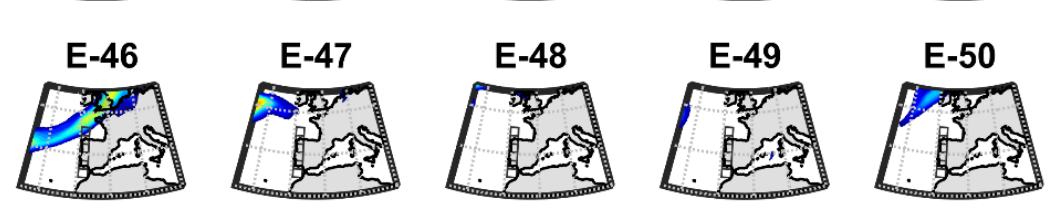




\section{POD $=$ HITS $/$ (HITS+MISSES) \\ FAR = FALSE $/$ (HITS+FALSE) \\ SR = HITS $/$ (HITS+FALSE) \\ BIAS = (HITS+FALSE) $/$ (HITS+MISSES)}

Figure S3. Metrics used in Figure 9: probability of detection (POD), Success Rate (RS), False Alarm Rate (FAR) and the BIAS. 